\title{
진로결정 자기효능감과 불확실성에 대한 인내력 부족에 따른 진로결정 차이
}

이아라(李아라)*

이주영(李周泳) ${ }^{* *}$

\section{논문 요약}

대학생 시기에는 진로결정이 중요한 발달 과업이므로 진로결정에 어려움이 있는 대학생들의 문제를 파악하여 그에 적합한 처치를 하는 것이 중요하다. 문제에 따라 차별적인 처치를 하기 위해서는 다양한 차원에서의 유형화 를 통해 이들이 경험하는 문제의 현상과 원인을 이해할 필요가 있다. 이에 본 연구는 진로결정 자기효능감과 불확실성에 대한 인내력부족을 동시에 고려한 이차원적 유형화를 통해 각 유형별로 진로미결정의 수준과 진로 결정문제의 내용을 파악하고자 하였다. 이를 위해 12 개 대학에 재학 중인 250 명의 대학생에게 불확실성에 대한 인내력 부족, 진로결정 자기효능감, 진로결정수준, 진로준비행동, 진로결정문제에 대한 설문을 실시하였고 이 중 238 명의 자료를 분석하였다. 연구 결과 연구대상자들을 진로결정 자기효능감과 불확실성에 대한 인내력 부 족 수준에 따른 네 가지 유형으로 구분할 수 있었으며, 각 유형별로 진로결정수준과 진로준비행동, 진로결정문제 에서 차이가 있는 것을 알 수 있었다. 이러한 결과는 내담자의 미결정 문제를 해결하는 데 있어서 진로결정 자기 효능감 뿐 아니라 불확실성을 인내하는 수준을 함께 고려하여 도움을 줄 수 있음을 의미하는 것이다. 이러한 연구 결과를 토대로 추후 연구가 필요한 영역을 제시하고, 개입방향에서의 시사점을 논의하였다.

주요어 : 진로결정자기효능감, 불확실성에 대한 인내력부족, 유형화, 진로결정수준, 진로결정문제, 진로준비 행동 


\section{I . 서론}

진로결정은 대학생들이 가지는 가장 중요한 발달과업 중 하나로, 대학생 시기는 자신의 직업 정체감을 형성하고 진로준비행동을 하며, 진로의 방향을 설정하는 가장 핵심적인 시기이다. 따 라서 이 시기 자신의 진로를 결정하지 못하고, 적절한 진로준비행동을 하지 못하는 대학생들을 돕는 것은 매우 중요하다.

다양한 진로결정 문제를 가진 학생들을 돕기 위한 맥락으로 연구자들은 대학생들의 진로미결 정과 미결정 학생들이 가지는 어려움에 대해서 관심을 가졌다. 진로미결정은 진로를 결정하지 못한 상태로, 직업이나 진로에 대한 다양한 어려움과 특성을 포함하는 복잡한 심리상태를 의미 한다(Lucas, 1993). 학자들은 이러한 미결정에 어떠한 요인들이 영향을 미치는지 확인하고자 노 력하였는데, 국내에서는 성, 학년, 가정형편 등의 인구통계학적 변인과 진로정체감, 자아정체감, 의사결정유형, 애착 등의 사회·심리학적 변인들이 관련되어 주로 연구되었다(정애경, 김계현, 김 동민, 2008). 또한 불안(Fuqua, Newman, \& Seaworth, 1988; O'Hare \& Tamburrim. 1986), 역기 능적 진로사고(Dodge, 2001), 진로정체감(Tokar, Withdrow, Hall, \& Moradi, 2003) 등의 변인 역시 진로미결정과 관련되어 미결정의 문제를 설명하는데 주로 사용되었던 요인들이다.

특히 진로결정 자기효능감은 진로미결정과 관련된 요인들 중에서도 큰 효과크기로 진로미결 정에 영향력을 보이는 변인으로 고려되고 있다(김수지, 이정자, 2013; 정애경 등, 2008). 진로결정 자기효능감은 진로결정과 관련한 여러 문제들을 수행할 수 있는지에 대한 개인의 신념(Hackett \& Betz, 1981)을 의미하는 개념으로 진로준비행동에 긍정적인 영향을 주고(Blustein, Devenis, \& Kidney, 1989; Gushue, Scanlan, Pantzer \& Clarke, 2006), 진로결정에 직접적인 영향을 줄 뿐 아니라, 관련 변인들과 진로결정의 관계를 매개하는 역할을 한다(유지선, 백민정, 2004; 홍혜영, 안혜선, 2009). 관련된 연구들은 개인이 자신에 대해 이해하고, 직업정보를 찾으며, 목표를 선택 하고 문제를 해결할 수 있다고 믿을수록, 실제 필요한 정보를 찾으려고 노력하고 결정에 대해 확신을 가지게 된다는 것을 강조한다. 즉 개인이 가지고 있는 진로와 관련된 인지적 신념이 진로 결정에 중요한 역할을 한다는 것이다.

그러나 진로미결정과 관련된 문제는 인지적인 요인만으로 설명하기에는 한계가 있다. 진로결 정에 영향을 미치는 어려움에는 심리적인 문제들이 영향을 주고, 진로 미결정에는 인지와 정서, 태도, 행동 등의 요소들이 모두 관련되어 있기 때문이다(Norman, Mary, \& Joseph, 2006). 이처럼 진로를 결정하지 못한 대학생들이 인지적인 요인 뿐 아니라 비인지적 요인에 의해서도 많은 영 향을 받는다는 제언들은(Tak \& Lee, 2003; 이지원, 이기학, 2014 재인용) 미결정 문제를 이해하고 해결하기 위해서도 인지적 요인과 함께 비인지적인 특성이 함께 고려되어야 함을 시사한다.

이러한 비인지적 특성 중에서 최근 진로관련 연구에서‘불확실성에 대한 인내력 부족 
(Intolerance of Uncertainty)’이라는 개념이 관심을 받기 시작하였다. 불확실성에 대한 인내력 부 족은 '불확실한 상황에서, 실제 일어날 결과의 가능성과 상관없이 부정적으로 반응하는 경향 성'(Ladouceur, Gosselin, \& Dugas, 2000)을 의미하는 것으로, 불확실성에 대한 인지적 처리 뿐 아니라 비인지적 요인인 정서. 행동적 특성까지 포괄하는 변인으로 이해된다(Grenier, Barrette, \& Ladouceur, 2005).

불확실성에 대한 인내력 부족의 개념은 Krohne(1989)에 의해 스트레스 상황에서의 개인의 반 응과 관련하여 소개된 것으로, 위협적인 정보를 어떻게 처리하고 대처하는지 결정짓는 중요한 요소로 제언되어왔다. 이는 걱정(worry)을 발생시키는 가장 중요한 핵심요소로 파악되어 이해 되었고(Dugas, Gagnon, Ladouceur, Freeston, 1998), 따라서 일반화된 불안장애(Generalized Anxiety Disorder)와 같은 정서 장애를 이해하고 치료하려는 목적의 연구들에 의해 다루어져 왔 다. 또한 불확실성에 대한 인내력 부족은 자신감과 통제감에는 부정적인 영향을 주고(Dugas, Freeston \& Ladouceur, 1997), 문제 해결 지향과 부적상관을 보이는 등(설승원, 오경자, 2008), 광범위한 불안과 우울 같은 심리적 건강에 영향을 준다는 것이 검증되었다.

최근 진로상담 연구자들은 위와 같은 개념이 개인의 진로결정과도 관련이 있음을 제언하고 있는데, 불확실성에 대한 인내력 부족이 진로장벽의 지각을 직. 간접적으로 높이고(김나래, 이기 학, 2012), 진로정체감과 부적상관을 보이며(김기숙, 2010), 진로선택 과정 자체를 위협적으로 지 각하고 높은 스트레스를 경험할 수 있도록 한다는(Buhr \& Dugas, 2002) 연구들이 그 예이다.

불확실성에 대한 인내력 수준이 이렇게 진로와 연결되어 영향을 미치는 중요한 이유 중 하나 는 바로 진로결정이 하나의 '선택'이라는 개념으로 이해되기 때문이다. 개인이 무엇을 선택하는 상황에서는 반드시 불확실성을 경험할 수밖에 없고, 그 선택이 중요할수록 그 불확실성과 불확 실성으로 인한 불편함이 커지게 된다. 같은 맥락에서, 대학생들에게 진로결정이 아주 중요한 선 택과정이라면, 필수적으로 경험할 수밖에 없는 불확실성에서 오는 불편함 역시 매우 커지게 되 기 때문에 이를 어떻게 대처하는지가 보다 중요해지는 것이다. 이 때, 불확실성을 인내하지 못하 고 이를 피하려고 대처하게 된다면 강박적 행동을 하거나 끊임없는 정보를 요구하면서도 정작 문제에는 접근하지 못하는 행동을 하게 되고(Freeston, Rheaume, Letarte, Dugas., \& Ladouceur, 1994), 진로상황에서 불안함이 커져 진로 결정을 하지 못하며(Gati et al., 2011; Saka, Gati, \& Kelly, 2008), 결정을 미루는 지연 행동(Gati et al., 2011; Saka et al., 2008)을 하게 될 수 있다. 따라서 본 연구에서는 기존 미결정 연구에서 중요하게 여겨진 진로결정 자기효능감과 결정상 황의 특성상 진로문제에 중요한 영향을 미칠 것으로 예상되는 불확실성에 대한 인내력을 동시 에 고려하여 대학생들의 결정 문제를 파악하고자 하였다. 이러한 시도는 진로와 관련된 단일한 변인으로 내담자의 문제를 진단하고 개입하는 것의 한계를 보완해줄 수 있다. 김봉환, 김계현 (1997)은 진로 상담 시 단일 변인으로만 내담자의 진로 특성을 판단하게 되면 내담자가 보이는 
문제행동을 이해하는데 한계가 있어 적절한 개입을 하기 어렵다고 하였다. 진로결정에서 동일한 문제를 호소하는 경우라도 진로 관련 행동을 다르게 할 수 있으며, 이러한 경우에는 서로 다른 차별적 처치가 필요하다는 것이다. 또한 동일하게 진로 미결정의 문제를 호소하는 개인이라도 그 원인이 성격적인 문제 때문일 수도 있고, 아직 진로를 결정할 시기가 아니라는 판단 때문일 수도 있다(Hartman, Fuqua, \& Hartman, 1983). 이처럼 진로미결정은 사람들마다 다양한 원인을 가지고 있는 다차원적인 문제이므로(Fuqua, Blum, \& Hartman, 1988), 미결정 대상자들을 적절 하게 돕기 위해서는 여러 중요 요인들을 함께 고려하여 이들의 진로발달과 결정을 이해하는 것 이 필요하다. 중요한 요인들을 함께 고려하여 서로 다른 차원에서의 유형을 발견하고 그 특성을 이해하는 것은 이들에 맞는 적절한 진로상담 전략을 구상하는데 중요한 시사점을 제공해 줄 수 있다(김연중, 손은령, 2012). 본 연구 역시 미결정에 영향을 줄 것으로 예상되는 변인을 동시에 고려하여 유형화 하고 각 유형의 특성을 확인함으로써, 이상의 중요성에 동의한 여러 연구자들 (김연중, 손은령, 2012; 김지선, 2012; 이제경, 1997; 임지영, 2009; 유은주, 2007; 진미경, 2000)과 맥락을 같이 한다.

보다 구체적으로 본 연구는 진로 관련 특성 중에서 진로결정 관련 문제의 내용과 진로준비행 동의 정도에 초점을 두었다. 진로결정문제란 진로 의사결정 과정에서 개인이 경험하는 어려움이 어떠한 부분에 있는지를 의미하는 개념으로(Gati, Krausz, \& Osipow, 1996), 이러한 결정문제의 구체적인 내용을 이해하는 것은 대학생들이 경험하는 진로문제를 보다 심층적으로 파악하여 차 별적인 상담 개입을 하기 위해 필수적이다(Meyer \& Winer, 1993). 기존의 연구자들의 노력을 통해 진로 결정 유무, 혹은 진로 결정의 수준을 측정하고 미결정 상태에 관심을 기울일 수 있었 다면, 이제는 미결정의 원인과 미결정 문제의 양상의 개인차를 파악하고 이에 차별적 처치를 하 는 시도가 뒷받침 될 필요가 있다. 또한 본 연구에서는 각 유형이 ‘무엇이 문제인지'를 확인함과 함께 ‘어떻게 하고 있는지'를 확인하고자 하였다. 개인의 진로 목표를 성취하기 위한 행동 차원 의 노력을 의미하는(김봉환, 1997) 진로준비행동은 합리적이고 효율적인 진로목표 달성에 매우 중요한 차원으로 여겨진다. 본 연구에서 유형에 따라 어떠한 진로준비행동을 보이고 있는지 살 펴보는 것은 진로와 관련된 내면적 이해와 더불어 외현적 특성을 통합적으로 이해할 수 있도록 돕고, 궁극적으로 적극적 준비행동에 대한 개입이 필요한 개인을 파악하는데 도움이 될 것이다.

요약하면 본 연구에서는 진로결정 자기효능감과 불확실성에 대한 인내력의 두 차원에 따라 대학생들을 이차원으로 유형화 하고, 유형에 따라 진로준비행동과 결정 수준, 진로결정 문제가 달라지는지를 확인하고자 하였다. 특히 각 유형이 가지는 진로결정문제와 행동적 특성에서의 차 이점을 확인하고, 유형에 따라 이들의 결정문제를 해결하고자 할 때 어떠한 개입이 보다 적절할 지에 대한 시사점을 마련하고자 한다.

본 연구의 연구문제는 다음과 같다. 
첫째, 불확실성에 대한 인내력 수준과 진로결정 자기효능감 정도에 따라 진로 결정 수준과 진로준비 행동에 차이가 있는가?

둘째, 불확실성에 대한 인내력 수준과 진로결정 자기효능감 정도에 따라 진로 미결정 원인에 차이가 있는가?

\section{ㅍ. 연구방법}

\section{1. 연구대상}

본 연구를 위해 서울, 경기, 강원, 경상도 지역 소재 12 개 대학에 재학 중인 250 명을 대상으로 설문을 실시하였으며, 그 중 불성실하게 응답한 12 명을 제외한 238 명이 분석의 대상이 되었다. 분석 대상들의 성별에 따른 분포를 살펴보면, 남학생이 149 명(62.6\%), 여학생이 89명(37.4\%)으로 남학생이 더 많았다. 학년에 따른 분포에서는 1학년 57명(23.9\%), 2학년 98명(41.2\%), 3학년 39명 $(16.4 \%), 4$ 학년 44 명 $(18.5 \%)$ 으로 2학년이 가장 많았다.

\section{2. 측정도구}

1) 불확실성에 대한 인내력 부족

본 연구에서는 불확실성에 대한 인내력 부족을 측정하기 위해 Buhr와 Dugas(2002)가 사용한 척도를 이아라(2013)가 타당화 한 도구를 사용하였다. Buhr와 Dugas(2002)는 불확실성에 대한 인내력 부족을 '불확실한 상황에 대해서 정서적·인지적·행동적 수준에 있어 부정적으로 반응하는 경향성'으로 정의한 Freeston과 그의 동료들(1994)의 불확실성에 대한 인내력 부족 척도 (Intolerance of Uncertainty Scale)를 영문판으로 번안하여 타당화하였다. Buhr와 Dugas(2002)가 성인들을 대상으로 척도의 신뢰도를 확인한 결과, 내적 일치도가 .94, 검사-재검사 신뢰도는 .74 로 나타나 높은 신뢰수준을 보였다. 이는 Freeston 등(1994)이 보고한 검사의 신뢰도 수준(내적 일치도 .91, 검사-재검사 신뢰도 .78)과 유사하다. 이아라(2013)의 연구에서도 225명의 대학생과 직장인을 대상으로 척도를 타당화하였는데, 내적 일치도가 .92로 나타나 높은 신뢰수준을 보였 다. 본 연구에서의 내적 일치도도 .92로 높게 나타났다. 이아라(2013)는 척도를 번안하는 과정에 서 번역, 역번역, 전문가 평정을 실시하였으며, 요인분석을 통해 구인타당도를 확인함으로써 척 도를 내용적, 측정학적으로 타당화 하였다. 이아라(2013)에 따르면, 요인분석을 실시한 결과, 원 
척도를 개발한 Freeston과 그의 동료들(1994)의 분석결과와 마찬가지로 5요인 구조가 적합하였 다. 5 요인을 구체적으로 살펴보면, 불확실한 것은 피해야 한다는 신념, 불확실한 것이 나쁘다는 신념, 불확실한 것과 관련된 좌절과 그로 인한 스트레스, 불확실성을 막으려는 행동 반응이 이에 해당한다. 본 척도는 총 27 문항으로 5점 척도(1점='전혀 그렇지 않다'에서 5점='완전히 그렇다' 까지)로 구성되어 있고, 점수가 높을수록 불확실성에 대해서 인내하는 능력이 부족한 것을 의미 한다. 본 연구에서는 연구 결과의 해석을 용이하게 하기 위해 '인내력이 높음 혹은 낮음'으로 해석하여 결과를 설명하고자 한다.

\section{2) 진로결정 자기효능감}

본 연구에서 사용한 진로결정 자기효능감 척도는 이기학, 이학주(2000)가 Betz와 그의 동료들 (1996)의 CDMSES-SF를 번안한 것이다. CDMSES-SF는 Taylor와 Betz(1983)가 개발한 CDMSES(Career Decision-Making Self-Efficacy Scale)의 축약형으로 총 25문항으로 구성되어 있 고, 자기평가, 직업정보, 목표 선택, 미래 계획, 문제 해결의 5개 하위 요인을 포함하고 있으며, 5 점 척도(1점=’전혀 아니다'에서 5점='매우 그렇다’까지)로 응답하도록 되어 있다. 이기학, 이학 주(2000)는 360명을 대상으로 본 척도의 신뢰도를 확인하였는데, 그 결과 5 개 하위 요인 각각의 내적 일치도가 .68 .79로 높게 나타났으며, 전체 신뢰도 계수 역시 .92로 매우 높게 나타났다. 본 연구에서의 내적 일치도 역시 .88로 높게 나타났다.

\section{3) 진로결정수준 척도}

본 연구에서 진로결정수준을 측정하기 위해 Jones(1989)의 진로결정척도(Career Decision Profile)를 활용하였다. 진로결정척도는 총 24 문항으로 그 중 결정성 차원 문항(2문항)과 편안함 차원 문항(2문항)이 진로의사결정상태를 파악하는데 사용된다. 결정성 차원에 해당하는 문항들 은 개인이 진로를 결정한 정도에 대한 질문이고 편안함 차원의 문항들은 진로 결정 상태에 대한 개인의 편안함 정도를 확인하는 질문이다. 본 연구에서 역시 결정성과 편안함 차원의 문항을 사 용하여 내담자의 진로결정수준을 확인하고자 하였다. Jones(1989)의 연구에서는 결정성 차원의 검사-재검사 신뢰도가 .66, 편안함 차원의 검사-재검사 신뢰도가 .76으로 나타났다. 본 연구에서 는 이아라(2013)가 번안한 문항을 사용하였으며, 해당 연구에서는 내적합치도가 결정성 차원에 서 .65, 편안함 차원에서 .60으로 나타났다. 본 연구에서 결정성 차원의 경우 내적일치도가 .82, 편안함 차원에서는 81 로 높게 나타났으며, 본 척도의 구인타당도를 확인하기 위해 AMOS를 활 용하여 확인적 요인분석을 실시한 결과, 적합도 지수가 모두 타당하게 나타났다(NFI=.994, 
$\mathrm{CFI}=.996, \mathrm{TLI}=.978, \mathrm{RMSEA}=.081)$. 본 척도는 8점 척도(1점=’전혀그렇지 않다’부터 8점=’매우그 렇다'까지)로 응답하도록 되어 있다.

\section{4) 진로준비행동}

본 연구에서 진로준비행동을 측정하기 위해 김봉환, 김계현(1997)이 개발한 진로준비행동 검사 를 사용하였다. 김봉환, 김계현(1997)은 본 검사를 제작하기 위해 진로상담 사례 분석과 진로 결 정을 확신하는 대학생들의 면담 자료 활용 등을 통해 임상적 측면에서 타당성을 확보하였으며, 기존에 국외에서 개발된 검사 도구 수집 및 분석과 전문가 자문, 신뢰도 산출 등을 통해 내용 및 측정학적 측면에서 타당성을 확보하였다. 본 척도의 문항은 총 16 개이며, 5 점 척도( 1 점=‘전혀 아니다'부터 5점='매우그렇다'까지)로 응답하게 되어 있다. 김봉환, 김계현(1997)의 연구에서 293 명의 대학생을 대상으로 확인한 본 검사의 내적일치도는 .84, 반분 신뢰도는 .74, 검사-재검사 신 뢰도(2주)는 .82로 높은 신뢰수준을 보였다. 본 연구에서의 내적 일치도 역시 .87로 높은 편이다.

\section{5) 진로결정문제 척도}

본 연구에서 진로결정 문제의 내용과 수준을 확인하기 위해 김동준(1997)이 Gati와 그의 동료 들(1996)의 진로결정문제 척도(CDDQ; Career Decision Difficulties Questionnaire)를 번안한 도 구를 사용하였다. 김동준(1997)은 척도를 번안하고 예비조사하는 과정에서 측정학적 문제를 이 유로 원 척도의 44 문항 중 3 문항을 제외하여 3 개의 하위요인과 41 문항으로 9 점 척도(1점=`전혀 그렇지않다’부터 9점=`매우그렇다’까지)로 응답하도록 구성하였다. 3개의 하위요인은 준비성 부 족, 정보 부족, 모순된 정보이다. 준비성 부족은 동기부족, 우유부단, 역기능적 신념을 포함하며, 정보부족은 진로결정과정, 자신, 직업, 정보를 얻는 방법에 대한 정보가 부족한 경우를 의미하 고, 모순된 정보는 신뢰할 수 없는 정보와 내적 혹은 외적 갈등을 포함한다. 김동준(1997)의 연구 에서 척도의 내적일치도는 .94로 매우 높게 나타났다. 본 연구에서의 내적 일치도는 .96으로 역 시 높게 나타났다.

\section{3. 연구절차 \\ 1) 검사 실시}

검사를 실시하기 위해 표집대상 학교별 협조자를 선정하였다. 학교별 협조자들은 대부분 해 
당학교에서 강의를 하고 있는 강사 혹은 교수로 하였다. 설문지는 연구자가 직접 협조자를 만나 서 전달하거나 우편을 통해 전달하였다. 설문지를 전달할 때 연구의 취지와 검사 실시 절차에 대한 기본 사항들을 설명한 다음 검사를 실시하도록 안내하였다. 응답에 소요되는 시간은 약 20 분 정도였다. 검사 실시 후에는 협조자가 우편을 통해 연구자에게 전달하거나 연구자가 직접 협 조자를 찾아서 설문지를 수거하였다.

\section{2) 이차원적 진로유형의 구성}

김봉환(1997)은 진로 문제에 있어 진로결정수준과 진로준비행동이 중요함을 강조하면서 두 변인을 활용한 유형화를 통해 진로 상담을 원하는 내담자들을 보다 차별적으로 진단하고 처치 할 수 있음을 제언하였다. 김봉환(1997)은 연구대상자들을 유형화하기 위해 각 변인들의 중위수 를 구하여 중위수를 기준으로 두 변인 모두에서 중위수보다 높은 점수가 나오는 집단, 두 변인 모두에서 중위수보다 낮은 점수가 나오는 집단, 두 변인들 중 하나는 중위수보다 높은 점수가 나오고 다른 하나는 중위수보다 낮은 점수가 나오는 집단의 총 네 가지 집단으로 구분하고 각 집단의 특징을 기술하여 유형화하였다. 김봉환(1997)이 이차원적 유형화 방법을 제안한 이 후 여러 연구자들은 이에 따라 고등학생 혹은 대학생들을 두 가지 진로관련변인을 통해 유형화하 여 각 유형의 특성을 구체화함으로써 차별적 진단 및 처치에 유용한 연구결과들을 제시했다(김 연중, 손은령, 2012; 김지선, 2012; 이제경, 1997; 임지영, 2009; 유은주, 2007; 진미경, 2000). 이에 본 연구에서도 불확실성에 대한 인내력 수준과 진로결정 자기효능감의 이차원적 진로유형화를 김봉환(1997)의 방법과 동일한 방법으로 실시하였다. 즉, 불확실성에 대한 인내력 부족 $(\mathrm{M}=70.0929, \mathrm{SD}=16.10)$ 의 중위수 70점, 진로결정 자기효능감 $(\mathrm{M}=87.30, \mathrm{SD}=13.09)$ 의 중위수 87점 을 기준으로 하여 유형화하였으며, 그 틀은 [그림 1]과 같다.

불확실성에 대한 인내력

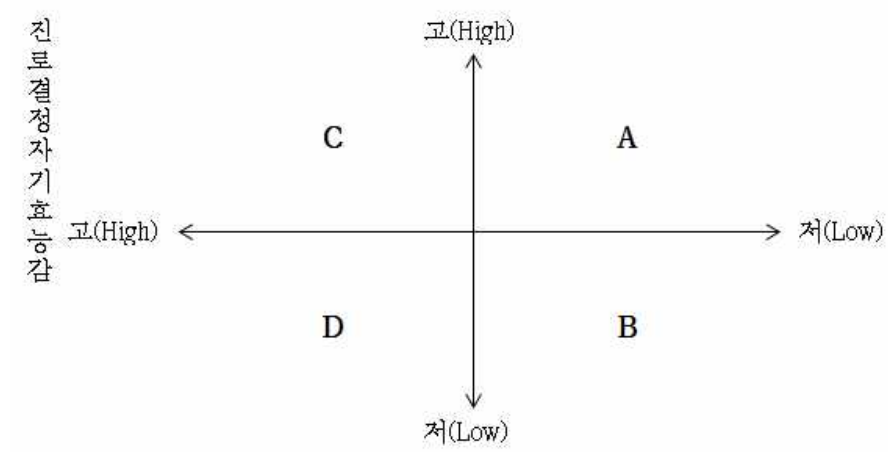

[그림 1] 불확실성에 대한 인내력 수준과 진로결정 자기효능감을 준거로 한 진로유형화 틀 
집단을 명명함에 있어, 유형화 명명의 타당성을 확보하기 위해 다음과 같은 과정을 거쳤다. 연구자들이 각 집단이 핵심적으로 보일 것이라고 생각되는 주요 특성을 기준으로 집단명명을 하였고, 한국상담학회 혹은 상담심리학회 전문가 자격증을 보유하고 있거나, 상담관련 박사학위 가 있는 상담전문가 5인에게 집단 명명에 대한 적합성과 타당성 검토를 부탁하였다. 전문가 검 토 결과 적합성과 타당성이 낮은 명명에 대한 의견을 수합하였고, 의견 수합 결과로 수정된 집단 명명에 대한 재검토를 부탁하여, 최종 집단 명명을 확정하였다.

우선 진로결정과 관련된 자신에 대한 믿음의 정도는 진로결정상황에서의 개인으로 하여금 자신감을 가지고 적극적으로 행동하게 하거나 혹은 위축되도록 하는데 영향을 준다. 따라서 진 로결정 자기효능감이 높은 경우 '자신있는' 유형으로, 진로결정 자기효능감이 낮은 경우 ‘위축 된' 유형으로 명명하였다. 다음으로 불확실한 상황에 대한 인내력은 진로결정 상황에서의 개인 으로 하여금 그 상황에서 인내하게 하거나 반대로 조급함을 가지도록 한다. 따라서 불확실성에 대해서 인내력이 높을수록 ‘인내형'으로, 불확실성에 대해서 인내력이 낮을수록 ‘조급형'으로 명 명하였다.

따라서 그림 1 에서 나타난 것처럼 불확실성에 대해 인내는 할 수 있지만 진로결정에 대해 효 능감은 낮은 A집단은 '위축된 인내형', 불확실성에 대해 인내를 하지 못하고 진로결정에 대해 효능감도 낮은 B집단은 '위축된 조급형', 불확실성에 대해 인내도 할 수 있고, 진로결정에 대해 효능감도 높은 C집단은 ‘자신있는 인내형', 진로결정에 대한 효능감은 높지만, 불확실성에 대해 인내하지 못하는 D집단은 ‘자신있는 조급형’이라고 명명하였다.

유형별 표본의 구성 분포를 살펴보면, $\mathrm{A}$ 유형(위축된 인내형)에는 $24.4 \%(\mathrm{n}=58), \mathrm{B}$ 유형(위축된 조급형)에는 $27.3 \%(\mathrm{n}=65), \mathrm{C}$ 유형(자신있는 인내형)에는 $26.1 \%(\mathrm{n}=62), \mathrm{D}$ 유형(자신있는 조급형)에 는 $22.3 \%(n=53)$ 가 분포하였다.

\section{4. 자료분석}

본 연구에서 수집한 자료로 진로유형에 따른 진로결정수준, 진로확신수준, 진로준비행동의 차 이와 진로미결정 이유에서의 차이를 확인하기 위해 ANOVA를 실시하고 사후검증으로 Scheffe 검증을 실시하였다. 


\section{III. 연구 결과}

1. 불확실성에 대한 인내력 수준과 진로결정 자기효능감의 이차원적 진로유형에 따른 진로결정수준, 진로확신수준의 차이

불확실성에 대한 인내력 수준과 진로결정 자기효능감의 이차원적 진로유형에 따른 진로결정 수준 $(F=12.557, p<.001)$, 진로확신수준의 차이 $(F=18.979, p<.001)$ 는 표 1 에서 볼 수 있듯이 통계적 으로 유의한 것으로 나타났다.

이차원적 진로유형들 간의 결정수준, 확신수준의 차이를 좀 더 자세히 알아보기 위해 scheffe 사후 검증을 실시한 결과, 결정수준에서는 $\mathrm{A}$ 유형 $(\mathrm{M}=11.36)$ 과 $\mathrm{B}$ 유형 $(\mathrm{M}=11.5566)$ 이 $\mathrm{C}$ 유형 $(\mathrm{M}=13.40)$ 과 $\mathrm{D}$ 유형 $(\mathrm{M}=13.62)$ 보다 낮은 것으로 나타났다( $\beta$ ×.05). 확신수준에서도 $\mathrm{A}$ 유형 $(\mathrm{M}=7.01)$ 과 $\mathrm{B}$ 유형 $(\mathrm{M}=7.20)$ 이 $\mathrm{C}$ 유형 $(\mathrm{M}=9.97)$ 과 $\mathrm{D}$ 유형 $(\mathrm{M}=10.15)$ 보다 낮은 것으로 나타났다( $\beta$ <.05).

<표 1> 불확실성에 대한 인내력 수준과 진로결정 자기효능감의 이차원적 진로유형에 따른 결정수준, 확신수준의 차이

\begin{tabular}{|c|c|c|c|c|c|c|}
\hline 구분 & 진로유형 & 사례수 & 평균 & 표준편차 & F & Scheffe \\
\hline \multirow{4}{*}{ 결정수준 } & A & 58 & 11.36 & 3.04 & \multirow{4}{*}{$11.151 * * *$} & \multirow{4}{*}{$A, B<C, D$} \\
\hline & B & 65 & 11.66 & 2.83 & & \\
\hline & $\mathrm{C}$ & 62 & 13.40 & 2.39 & & \\
\hline & D & 53 & 13.62 & 2.31 & & \\
\hline \multirow{4}{*}{ 확신수준 } & A & 58 & 7.01 & 3.27 & \multirow{4}{*}{$15.219 * * *$} & \multirow{4}{*}{$A, B<C, D$} \\
\hline & B & 65 & 7.20 & 3.31 & & \\
\hline & C & 62 & 9.97 & 3.18 & & \\
\hline & $\mathrm{D}$ & 53 & 10.15 & 3.70 & & \\
\hline
\end{tabular}

$* * * \mathrm{p}<.001$

2. 불확실성에 대한 인내력 수준과 진로결정 자기효능감의 이차원적 진로유형에 따른 진로준비행동의 차이

불확실성에 대한 인내력 수준과 진로결정 자기효능감의 이차원적 진로유형에 따른 진로준비 행동의 차이는 표 2에서 볼 수 있듯이 통계적으로 유의한 것으로 나타났다 $(F=13.247, p<.001)$. 이차원적 진로유형들 간의 진로준비행동의 차이를 좀 더 자세히 알아보기 위해 scheffe 사후 검 증을 실시한 결과, 진로준비행동에서 $\mathrm{A}$ 유형 $(\mathrm{M}=38.22)$ 과 $\mathrm{B}$ 유형 $(\mathrm{M}=41.22)$ 이 $\mathrm{C}$ 유형 $(\mathrm{M}=47.45)$ 과 $\mathrm{D}$ 유형 $(\mathrm{M}=50.38)$ 보다 낮은 것으로 나타났다( $p<.05)$. 
<표 2> 불확실성에 대한 인내력 수준과 진로결정 자기효능감의 이차원적 진로유형에 따른 진로준비행동의 차이

\begin{tabular}{|c|c|c|c|c|c|c|}
\hline 구분 & 진로유형 & 사례수 & 평균 & 표준편차 & $\mathrm{F}$ & Scheffe \\
\hline \multirow{4}{*}{$\begin{array}{c}\text { 진로 } \\
\text { 준비행동 }\end{array}$} & $A$ & 58 & 38.22 & 10.80 & \multirow{4}{*}{$12.848 * * *$} & \multirow{4}{*}{$A, B<C, D$} \\
\hline & B & 65 & 41.22 & 11.06 & & \\
\hline & $\mathrm{C}$ & 62 & 47.45 & 12.08 & & \\
\hline & D & 53 & 50.38 & 13.13 & & \\
\hline
\end{tabular}

${ }^{* * *} p<.001$

\section{3. 불확실성에 대한 인내력 수준과 진로결정 자기효능감의 이차원적 진로유형에 따라 인식하는 진로결정문제의 차이}

불확실성에 대한 인내력 수준과 진로결정 자기효능감의 이차원적 진로유형에 따른 진로결정 문제에서의 차이는 표 3 에서 확인할 수 있다. 준비성 부족에서는 .001수준에서 통계적으로 유의 한 차이가 있는 것으로 나타난다. 이 차이를 좀 더 자세하게 알아보기 위하여 scheffe검증을 실 시한 결과, 준비성 부족에서 $\mathrm{C}$ 유형 $(\mathrm{M}=26.90)$ 이 $\mathrm{B}$ 유형 $(\mathrm{M}=32.97)$ 과 $\mathrm{D}$ 유형 $(\mathrm{M}=31.40)$ 에 비해 더 낮게 나타났다( $p<.05)$. 정보 부족에서도 .001수준에서 통계적으로 유의한 차이가 있는 것으로 나 타났다. 이 차이를 좀 더 자세하게 확인하기 위해서 사후검증을 실시한 결과, 정보 부족에서 $\mathrm{C}$ 유 형(M=58.95)이 $\mathrm{A}$ 유형( $\mathrm{M}=75.62)$ 과 $\mathrm{B}$ 유형 $(\mathrm{M}=85.23)$ 에 비해 더 낮게 나타났으며, $\mathrm{D}$ 유형 $(\mathrm{M}=64.30)$ 이 $\mathrm{B}$ 유형 $(\mathrm{M}=85.23)$ 에 비해 더 낮게 나타났다( $p<.05)$. 모순된 정보에서도 .001수준에서 통계적으 로 유의한 차이가 나타났다. 이 차이를 좀 더 자세하게 확인하기 위해 사후검증을 한 결과, 모순 된 정보에서 $\mathrm{A}$ 유형 $(\mathrm{M}=59.38), \mathrm{C}$ 유형 $(\mathrm{M}=53.06), \mathrm{D}$ 유형 $(\mathrm{M}=58.94)$ 이 $\mathrm{B}$ 유형 $(\mathrm{M}=71.95)$ 에 비해 더 낮게 나타났다( $p \times .05)$. 
<표 3> 불확실성에 대한 인내력 수준과 진로결정 자기효능감의 이차원적 진로유형에 따라 인식하는 진로결정문제(준비성 부족, 정보 부족, 모순된 정보)의 차이

\begin{tabular}{|c|c|c|c|c|c|c|}
\hline 구분 & 진로유형 & 사례수 & 평균 & 표준편차 & $\mathrm{F}$ & Scheffe \\
\hline \multirow{4}{*}{$\begin{array}{c}\text { 준비성 } \\
\text { 부족 }\end{array}$} & $A$ & 58 & 29.84 & 6.74 & \multirow{4}{*}{$7.215 * * *$} & \multirow{4}{*}{$C<B, D$} \\
\hline & B & 65 & 32.97 & 7.30 & & \\
\hline & $\mathrm{C}$ & 62 & 26.90 & 8.78 & & \\
\hline & D & 53 & 31.40 & 7.42 & & \\
\hline \multirow{4}{*}{ 정보 부족 } & A & 58 & 75.62 & 23.95 & \multirow{4}{*}{$14.924 * * *$} & \multirow{4}{*}{$\begin{array}{c}C<A, B \\
D<B\end{array}$} \\
\hline & B & 65 & 85.23 & 19.46 & & \\
\hline & C & 62 & 58.95 & 25.45 & & \\
\hline & $\mathrm{D}$ & 53 & 64.30 & 27.08 & & \\
\hline \multirow{4}{*}{$\begin{array}{l}\text { 모순된 } \\
\text { 정보 }\end{array}$} & A & 58 & 59.38 & 22.71 & \multirow{4}{*}{$8.346 * * *$} & \multirow{4}{*}{$A, C, D<B$} \\
\hline & B & 65 & 71.95 & 21.73 & & \\
\hline & $\mathrm{C}$ & 62 & 53.06 & 19.64 & & \\
\hline & $\mathrm{D}$ & 53 & 58.94 & 23.92 & & \\
\hline
\end{tabular}

${ }^{* * *} p<.001$

\section{IV. 논의 및 결론}

본 연구는 진로결정 자기효능감과 불확실성에 대한 인내력 수준에 따라 대학생의 진로결정수 준과 진로준비행동, 진로결정 문제에 차이가 있는지 확인함으로써 두 변인에 대한 내담자의 특 성에 따라 차별적인 진로상담 개입에 대한 시사점을 마련하고자 진행되었다. 불확실성에 대한 인내력 수준과 진로결정 자기효능감의 수준에 따라 유형화 한 4 개 집단(A 유형: 진로결정 효능 감이 낮고, 불확실성에 대한 인내력은 높음; B 유형: 진로결정 자기효능감이 낮고, 불확실성에 대한 인내력도 낮음; C 유형: 진로결정 자기효능감이 높고, 불확실성에 대한 인내력도 높음; D 유형: 진로결정 자기효능감은 높으나, 불확실성에 대한 인내력은 낮음)의 특성에 대한 본 연구의 결과와 이에 대한 제언은 다음과 같다.

첫째, 진로결정수준과 진로결정의 확신수준, 진로준비행동의 수준은 진로결정 자기효능감이 높은 C유형(자신있는 인내형)과 $\mathrm{D}$ 유형(자신있는 조급형)이 진로결정 자기효능감이 낮은 $\mathrm{A}$ 유형 (위축된 인내형)과 $\mathrm{B}$ 유형(위축된 조급형)보다 높은 것으로 나타났다. 이러한 결과는 대학생들이 진로를 결정하는 수준과 그에 대한 확신 정도, 진로준비행동의 정도는 불확실성에 대한 인내력 수준의 차이보다는 진로결정 자기효능감의 수준에 따라 차이가 있다는 것을 보여준다. 이는 진 로결정 자기효능감이 진로준비행동과 결정수준에 긍정적인 영향을 미친다는 기존연구들 
(Blustein et al., 1989; Gushue et al., 2006; Hackett \& Betz, 1981)과 일치하는 결과로, 진로결정 에 대해서 스스로 문제를 해결하고 정보를 찾을 수 있다고 생각하는 학생들은 실제 진로준비를 더 많이 하고 스스로 선택한 진로에 대해서 보다 높은 확신을 가지고 있었다. 반면 같은 정도의 진로결정 자기효능감을 가진 집단에서 불확실성에 대한 인내력의 차이는 이러한 결정, 확신, 진 로준비행동의 차이를 야기하지 않았는데, 이는 불확실성에 대한 인내력 수준이 진로준비행동과 는 유의미한 상관을 나타내지 않았다는 선행연구(김경욱, 2009)와는 일치하는 결과이지만, 동일 한 연구에서 불확실성에 대한 인내력 수준이 진로결정수준과 유의미한 상관이 있는 것으로 나 타난 결과와는 차이가 있다.

두 번째로, 대학생의 진로결정 자기효능감과 불확실성에 대한 인내력 수준에 따라 개인이 보 이는 진로결정 문제에 차이가 있는지 확인한 결과, 같은 진로결정 자기효능감 수준이라고 하더 라도 진로결정 문제의 원인은 불확실성에 대한 인내력 수준에 따라 달라지는 것이 확인되었다. 구체적으로, $\mathrm{C}$ 집단(자신있는 인내형)과 $\mathrm{D}$ 집단(자신있는 조급형)은 두 집단 모두 진로결정과 관 련한 자기효능감이 높았으나, 불확실성을 인내할 수 있느냐에 따라 준비성 부족의 문제에서 차 이를 보였다. 즉 진로결정과 관련해 효능감이 높지만, 불확실성에 대해서는 인내하기 어려워하 는 집단은 진로결정에 대해 역기능적 신념을 가지고 있거나, 우유부단하며, 결정을 중요하게 생 각하지 않는 것으로 생각하는 경향이 높았다. 이러한 차이는 불확실성에 대해 인내력이 적을수 록 잘못된 선택에 대한 두려움이 크고(Pratt. Tallis, \& Eysenk, 1997), 따라서 혹시라도 있을지 모르는 실패를 피하려고 하는 경향으로 인해 확신이 생길 때까지 결정을 유예할 수 있다는 선행 연구(Metzger et al., 1990)의 제언으로 설명할 수 있다.

또한 진로결정 자기효능감이 낮은 두 집단 역시 불확실성에 대한 인내력의 차이에 따라 진로 결정 문제에 차이가 있었는데, 진로결정에 대해 자기효능감이 낮으면서 불확실성을 인내하지 못 하는 집단(B ‘위축된 조급형')은 불확실성을 인내할 수 있는 집단(A ‘위축된 인내형')보다 모순된 정보를 처리하는 문제를 더 많이 보고하는 것으로 나타났다. 즉, 진로결정 자기효능감이 낮으면 서 불확실성을 인내하지 못하는 경우, 신뢰할 수 없는 정보나 애매한 정보를 통합하고 처리하는 데 더욱 취약하며 내적 혹은 외적 갈등을 크게 경험하는 것으로 보인다. 이러한 차이 역시 불확 실성에 대한 인내력이 낮은 경우 모호한 정보를 더욱 위협적으로 지각하고(Ladouceur, Freeston, \& Dugas, 1993), 이러한 정보를 처리할 때 더욱 민감하게 반응할 수 있다는 맥락(Pratt et al., 1997)에서 이해할 수 있다.

지금까지 살펴본 바와 같이, 본 연구결과에서는 진로결정 및 확신 수준과 진로준비행동 수준 의 경우에는 진로결정 자기효능감 수준에 따른 차이만 유의미하였으나, 진로결정과 관련된 문제 의 경우에는 진로결정 자기효능감과 불확실성에 대한 인내력 수준에 따른 이차원적 유형화 집 단 간에 차이가 유의하게 나타났다. 이러한 결과는 진로상담 내담자의 결정문제를 보다 구체적 
으로 확인하는데 있어 진로결정 자기효능감 뿐 아니라 불확실성에 대한 인내력 수준도 함께 고 려할 필요가 있음을 시사하는 결과로 보인다. 다시 말해, 진로결정 자기효능감만을 고려했을 때 내담자의 진로결정수준과 준비행동의 수준을 예측할 수 있으나, 이들이 결정과정에서 가지는 문 제가 어떻게 달라지는지 이해하기에는 어려움이 있을 수 있다. 그러나 불확실성에 대한 인내력 의 정도를 같이 고려한다면, 진로상담에서 내담자가 가지는 미결정 문제를 보다 구체적으로 이 해할 수 있게 되고, 이는 보다 적절한 개입이 가능하도록 하는데 도움이 될 것이다.

예를 들어, $\mathrm{D}$ 유형(자신있는 조급형)의 경우 진로결정 자기효능감이 높기 때문에 효능감이 낮 은 학생들에 비해서는 상대적으로 결정과 확신의 수준이 높고 진로준비를 성실하게 해 나가는 특성을 가졌으므로 전형적인 진로상담 내담자의 유형으로 인식되지 않을 수 있다. 그러나 본 연 구결과에서 $\mathrm{D}$ 유형(자신있는 조급형)은 $\mathrm{C}$ 유형(자신있는 인내형)과 비교했을 때 진로결정문제 중 준비성 부족에서 유의미한 차이를 보였다. 이는 $\mathrm{D}$ 유형이(자신있는 조급형) 같은 수준의 효능감 을 가진 학생들에 비해서 부정적 결과가 포함되는 모호하고 불확실함이 없는 상태, 즉 진로와 관련된 완벽한 선택을 해야 한다는 생각을 가질 수 있음을 의미한다. 이들은 높은 효능감에도 불구하고, 자신의 결정과 선택이 혹시 잘못 될 수 있을 것에 대한 두려움을 가질 수 있다. 또한 불확실성에 대한 낮은 인내력은 불안을 야기하는 주요 원인이 되므로(Krohne, 1993), 이들은 실 패하지 않는 선택을 해야 한다는 불안과 더 좋은 진로선택에 대한 스트레스를 경험할 가능성이 있다. 진로와 관련된 비합리적인 신념과 불안이 적절하고 합리적인 진로선택을 방해한다는 제언 (Osborn, 1998; Saka \& Gati, 2007)은 D유형(자신있는 조급형) 집단을 위한 진로상담 개입이 간 과되어서는 안된다는 것을 의미하는 것이다. 특히 의사결정에서 중요한 것이 단지 결정이 이루 어졌느냐의 문제를 넘어서서, 문제 없는 선택(problem-free choosing)을 하는 것이 중요하고 (Phillips, 1992), 이를 위해서는 의사결정에 대한 평가가 결정의 결과 뿐 아니라 결정의 과정에서 도 고려해야 한다는 것을 생각할 때(Gelatt, 1989), D유형(자신있는 조급형)의 집단이 표면적으로 보여지는 적극성 이면에 있는 조급함과 불안의 문제를 이해하고 개입하는데 본 연구의 유형화 가 도움이 될 것으로 생각된다.

한편 진로결정 자기효능감은 낮지만 불확실성에 대해서 인내할 수 있는 $\mathrm{A}$ 유형(위축된 인내 형)의 경우를 살펴보면, 이들은 진로결정문제에 있어 효능감을 높이는 개입과 동시에 진로와 관 련된 정보 부족 문제를 해결하는 개입이 보다 필요할 것으로 보인다. 이들은 진로결정에 대한 스스로의 능력에 대한 믿음이 부족함으로 인해 실제 진로결정을 하지 못하고, 결정한 것에 대해 서도 확신하지 못하며, 진로와 관련된 행동을 적절하게 하고 있지 않은 것으로 나타났다. 효능감 의 부족이 행동에 대해 동기를 가져오지 못하고, 행동의 부족은 궁극적으로 진로결정과 관련해 서 필요한 정보들을 탐색할 기회를 가지지 못하게 할 수 있다. 따라서 이들을 상담하는 과정에서 는 관찰학습, 인지치료, 긍정적 질문의 활용(박은선, 2010) 등의 방법을 통해 결정에 대한 자기효 
능감을 증진시키는 한편 구체적인 직업정보 탐색 방법의 교육, 자기 이해와 직업세계의 탐색을 돕는 프로그램에의 참여, 합리적인 결정과정에 대한 도움이 함께 제공될 필요가 있다.

이에 더해, $\mathrm{B}$ 유형(위축된 조급형)의 경우, 진로결정 자기효능감이 낮고, 동시에 불확실성을 인 내하지 못함으로 인해 $\mathrm{A}$ 유형(위축된 인내형)이 가지는 문제들에 더해 모순된 정보를 처리하고 서로 다른 의견이나 기준을 내적으로 통합하는 과정에서의 어려움을 보다 크게 경험하는 것으 로 보인다. 이 유형은 진로결정 문제의 모든 영역에서 가장 큰 문제를 보이는 영역으로 다양한 측면에서의 개입이 필요하다. 서로 다른 기준이나 불일치한 정보를 통합하기 위해서는 진로와 관련된 긍정적 정보, 부정적 정보들을 동시에 인지하고 명확하지 않은 차이에도 불구하고 우선 순위를 정할 수 있어야 한다. 그러나 불확실성에 대한 인내력이 낮은경우 부정적인 자극에 대해 서 효율적으로 자원배분을 하기 어렵고(이아라, 2013), 인지적 편향에 의해 여러 정보로부터 오 는 혼란감을 높일 수 있다는 제언(Butler \& Booth, 1991)을 고려했을 때, 이들이 정보를 얼마나 탐색하는지를 확인하는 것 뿐 아니라 정보를 어떻게 받아들이고 불일치한 정보들을 어떻게 처 리하고 있는지 이해하고, 혼란감을 줄일 수 있도록 돕는 개입이 추가적으로 필요할 것으로 생각 된다.

본 연구의 결과는 진로상담에서 대학생들의 진로결정 자기 효능감을 높이게 도와주는 것 뿐 아니라 진로선택과 결정이 가져올 수 있는 불확실성을 인내할 수 있도록 돕는 것이 결정문제를 파악하고 미결정의 문제를 해결하는데 보다 도움이 될 수 있음을 시사한다. 특히 진로결정에서 중요하다고 제언되고 있는 인지적, 정서·성격적 변인에 따라 대학생들의 진로결정수준과 준비행 동수준, 나아가 구체적인 진로결정 문제의 내용이 어떻게 다른지 파악함으로써 유형에 따라 어 떠한 개입이 필요할지에 대한 시사점을 제공할 것으로 기대한다.

또한 본 연구는 대학생들이 가지는 불확실성에 대한 인내력의 정도를 구체적인 진로 결정 관 련 변인과 고려하여 탐색했다는 데 의의가 있다. 최근 진로상담 연구들에서는 불확실성이나 우 연이 진로발달에 중요한 역할을 하며(손은령, 2009; Mitchell, Levin, \& Krumboltz, 1999), 불확실 하고 모호한 상황에서의 인내력 부족이 진로미결정과 관련이 있음을(Gati et al., 2011) 밝히고 있으나, 구체적으로 결정문제와 어떻게 관련이 되는지는 충분히 설명하지 못하고 있다. 본 연구 에서는 대학생이 가지는 불확실성에 대한 인내력 정도와 결정과정에서의 구체적 문제를 연결해 확인해 봄으로써 해당 변인이 진로관련 상황에서 중요하게 고려될 수 있음을 설명하는 하나의 근거가 될 수 있을 것이다.

이러한 연구의 의의에도 불구하고 본 연구에는 제한점이 존재한다. 이에 본 연구의 제한점을 고려하여 다음과 같이 후속 연구를 위한 제언을 하고자 한다. 첫째, 본 연구는 연구대상이 편의 표집이 되었고, 대상의 분포가 학년별, 성별로 균등하지 못한 점이 있으므로 연구 결과를 일반화 하는데 한계가 있을 수 있다. 따라서 이에 대한 추후 보완적인 연구가 필요할 것으로 보인다. 
둘째, 본 연구에서는 불확실성에 대한 인내력 수준이 진로결정 자기효능감의 영향력을 고려했을 때 진로결정수준의 차이에 영향을 미치지 않은 것으로 나타났으나, 이는 불확실성에 대한 인내 력 수준이 진로결정 수준에 영향을 미친다는 선행연구(김경욱, 2009) 결과와 차이가 있다. 이러 한 차이는 진로결정수준 도구의 차이, 함께 고려한 변인의 차이 등에서 기인한 것일 수 있다. 따라서 이러한 연구 결과의 불일치에 대한 명확한 이해를 위해서는 향후 다양한 측정 도구와 변인을 고려한 후속적 연구가 필요하다. 셋째, 본 연구에서 유형화를 위해 각 변인의 중위수를 기준으로 높고 낮은 집단을 구분하였으므로 중위수에 가까운 수준을 나타내는 연구대상자들까 지 각 변인의 수준이 높거나 낮은 수준의 유형으로 분류되었다. 이로 인해 각 유형의 특성이 약 화될 수 있으며 각 변인의 중간 수준을 보이는 경우가 유형화되지 않아 또 다른 유형에 대한 탐색을 하지 못한 한계가 있다. 이는 실제 상담현장에서 내담자를 이해할 때, 본 연구에서 제안 한 유형을 통한 내담자 특성을 이해하되 내담자가 가지는 변인의 수준에 따라 유연성 있는 해석 을 해야 할 필요성이 있음을 의미한다. 또한 추후 연구에서는 보다 많은 자료를 수집하고 정교한 분석방법을 활용하여 보다 다양한 유형이 존재하는지 탐색해 볼 필요가 있을 것이다. 


\section{참고문헌}

고내숙, 유금란(2014). 역기능적 진로사고와 정서경험 군집에 따른 진로결정자기효능감 차이. 한 국심리학회지: 상담 및 심리치료. 26(2), 441-458.

김경욱(2009). 자기효능감과 불확실성에 대한 인내력 부족이 진로준비행동 및 진로결정 수준에 all는 영향: 진로성취목표의 매개효과를 중심으로. 한국심리학회지: 상담 및 심리치 료, 21(2), 501-519.

김기숙(2010). 내외통제성과 불확실성에 대한 인내력이 학교적응에 미치는 영향 - 진로정체감을 매개변인으로-. 석사학위논문, 고려대학교.

김나래, 이기학(2012). 불확실성에 대한 인내력 부족과 지각된 진로장벽의 관계 : 사회비교 경향 성과 부정적 평가에 대한 두려움의 매개효과 검증. 산업교육연구, 31(4), 111-134. 김동준(1997). 진로미결정 문제와 심리적 변인의 관계. 석사학위논문, 충북대학교. 김봉환(1997). 대학생의 진로결정수준과 진로준비행동의 발달 및 이차원적 유형화. 박사학위논 문, 서울대학교.

김봉환, 김계현(1997). 대학생의 진로결정수준과 진로준비행동의 발달 및 이차원적 유형화. 한국 심리학회지: 상담 및 심리치료, 9(1), 311-333.

김종운, 박성실(2014). 대학생의 정서지능과 진로결정의 관계에서 진로결정자기효능감과 진로장 벽의 매개효과. 상담학연구, 15(1), 279-300.

김수지, 이정자(2013). 진로장벽, 진로결정자기효능감이 진로준비행동에 미치는 영향. 재활심리 연구, 20(1), 119-136.

김연중, 손은령(2012). 대학생의 지각된 진로장벽과 진로결정자기효능감의 이차원적 진로유형과

학습행동과의 관계. 상담학연구, 13(5), 2443-2461.

박은선(2010). 아버지의 특성과 긍정적 인지와 질문이 대학생의 진로탐색 자기효능감과 진로탐 색행동에 미치는 영향. 상담학연구, 11(3), 1117-1136.

설승원, 오경자(2008). 불확실성에 대한 인내력 부족과 정서 통제감이 걱정에 영향을 미치는 기 제: 문제 해결 지향의 매개효과를 중심으로. 한국심리학회지:임상, 27(1), 209-235. 이기학, 이학주(2000). 대학생의 진로 태도 성숙 정도에 대한 예언 변인으로서의 자기-효능감 효 과 검증에 대한 연구. 한국심리학회지: 상담 및 심리치료, 12(1), 127-136.

이아라(2013). 진로 불확실성에 내포된 부정적 결과에 대한 수용-회피 기반 처치가 한국 대학생 의 진로탐색과정에 미치는 영향. 박사학위논문, 서울대학교.

이지원, 이기학(2014). 대학생의 성인애착과 진로의사결정문제와의 관계: 정서적 어려움의 매개 효과를 중심으로. 한국심리학회지: 학교. 11(1), 55-87. 
정미나, 엄정혜, 성벼리, 양은주(2011). 청소년의 심리적 유형에 따른 진로장벽 지각의 차이: 내외 통제성 및 불확실성에 대한 인내력을 중심으로. 한국심리학회지: 학교, 8(3), 359-377. 정애경, 김계현, 김동민(2008). 진로미결정 및 관련변인에 관한 국내연구 메타분석. 상담학연구, 9(2), 551-564.

Betz, N. E., Klein, K. L., \& Taylor, K. M. (1996). Evaluation of a short form of the Career Decision-Making Self-Efficacy Scale. Journal of Career Assessment, 4(1), 47-57.

Braunstein-Bercovitz, H., Benjamin, B. A., Asor, S., \& Lev, M. (2012). Insecure attachment and career indecision: Mediating effects of anxiety and pessimism. Journal of Vocational Behavior. 81, 236-244.

Buhr, K., \& Dugas, M. J. (2002). The intolerance of uncertainty scale: psychometric properties of the English version. Behavior Research and Therapy, 40, 931-945.

Butler, G., \& Booth, R. G. (1991). Developing psychological treatments for generalized anxiety disorder. In R. M. Rapee \& D. H. Barlow (Eds.). Chronic anxiety: Generalized anxiety disorder and mixed anxiety-depression. (pp. 187-209). New York, NY, US: Guilford Press.

Dugas, M. J., Gagnon, F., Ladouceur, R., \& Freeston, M. H. (1998). Generalized anxiety disorder: A preliminary test of a conceptual model. Behavioral Research and Therapy, $36,215-226$.

Dugas, M. J., Freeston, M. H., \& Ladouceur, R. (1997). Intolerance of uncertainty and problem orientation in worry. Cognitive Therapy and Research, 21, 593-606.

Freeston, M. H., Rheaume, J., Letarte, H., Dugas, M. J., \& Ladouceur, R. (1994). Why do people worry?. Personality and individual Differences, 176), 791-802.

Fuqua, D. R., Blum, C. R., \& Hartman, B. W. (1988). Empirical support for the differential diagnosis of career indecision. Career Development Quarterly, 36, 364-373.

Fuqua, D. R., Newman, J. L., \& Seaworth, T. B. (1988). Relation of state and trait anxiety to different components of career indecision. Journal of Counseling Psychology, 35(2), 154-158.

Gati, I., Krausz, M., \& Osipow, S. H. (1996). A taxonomy of difficulties in career decision making. Journal of Counseling Psychology, 43, 510-526.

Gati, I., Gadassi, R., Saka, N., Hadadi, Y., Ansenberg, B., Friedman, R., Asulin-Peretz, L. (2011). Emotional and personality-related aspects of career decision making difficulties: Facets of career indecisiveness. Journal of Career Assessment, 19, 3-20.

Gelatt, H. B. (1989). Positive uncertainty: A new decision making framework for counseling. 
Journal of Counseling Psychology, 36, 252-256.

Grenier, S., Barrette, A. M., \& Ladouceur, R. (2005). Intolerance of uncertainty and intolerance of ambiguity: Similarities and differences. Personality and Individual Differences, 39, 593-600.

Gushue, G. V., Scanlan, K. R., Pantzer, K. M., \& Clarke, C. P. (2006). The relationship of career decision-making self efficacy, vocational identity, and career exploration behavior in African American high school students. Journal of Career Development, 33, 19-28.

Hackett, G., \& Betz, N. E. (1981). A self-efficacy approach to the career development of women. Journal of Vocational Behavior, 18, 326-339

Hartman, B. W., Fuqua, D. R., \& Hartman, P. T. (1983). The predictive potential of the career decision scale in identifying chronic indecision. Vocational Guidance Quarterly, 31, 103-108.

Jones, L. K. (1989). Measuring a three-dimensional construct of career indecision among college students: A revision of the vocational decision scale- The Career Decision Profile. Journal of Counseling Psychology, 36(4), 477-486.

Krohne, H. W. (1993). Vigilance and cognitive avoidance as concepts in coping research. In H. W. Krobne, Attention and Avoidance[[[19-50]. Toronto. Gorringen: Hogrefe \& Huber.

Ladouceur, R., Gosselin, P., \& Dugas, M. J. (2000). Experimental manipulation of intolerance of uncertainty: a study of a theoretical model of worry. Behaviour Research and Therapy, 38, 933-941.

Lucas, M. S. (1993). A validation of types of career indecision at a counseling center. Journal of Counseling Psychology, 40(4), 440-446.

Metzger, R. L., Miller, M. L., Cohen, M., Sofka, M., \& Borkovec, T. D. (1990). Worry changes decision making: The effect of negative thoughts on cognitive processing. Journal of Clinical Psychology, 46, 78-88.

Meyer, B. W., \& Winer, J. L. (1993). The Career decision scale and neuroticism. Journal of Career Assessment, 1, 171-180.

O'Hara, M. M., \& Tamburri, E. (1986). Coping as a moderator of the relation between anxiety and career decision making. Journal of Counseling Psychology, 33(3), 255-264.

Osborn, D. S. (1998). The relationship among perfectionism, dysfunctional career thoughts and career indecision. Doctoral dissertation, Florida State University. 
Phillips, S. D. (1992). Career counseling: Choice and implementation. In S. D. Brown \& R. W. Lent, Handbook of Counseling Psychology(2nd), 513-547, New York: John Wiley \& Sons, Inc.

Pratt, P., Tallis, F., \& Eysenk, M. (1997). Information-processing, storage characteristics and worry. Behaviour Research and Therapy, 35, 1015-1023.

Saka, N., \& Gati, I. (2007). Emotional and personality-related aspects of persistent career decision-making difficulties. Journal of Vocational Behavior, 71, 340-358.

Saka, N., Gati, I., \& Kelly, K. R. (2008). Emotional and personality-related aspects of career decision making difficulties. Journal of Career Assessment, 16, 403-424.

Tak, J. K., \& Lee, K. H. (2003). Development of the Korean Career Indecision Inventory. Journal of Career Assessment, 11(3), 328-345.

Taylor, K. M., \& Betz, N. E. (1983). Applications of self-efficacy theory to the understanding and treatment of career indecision. Journal of Vocational Behavior, 22, 63-81.

Tokar, D. M., Withrow, J. R., Hall, R. J., \& Moradi, B. (2003). Psychological separation, attachment security, vocational self Concept crystalization, and career indecision: A structural equation analysis. Journal of Counseling Psychology, 50(1), 3-19.

* 논문접수 2014년 11월 4일 / 1차 심사 2014년 12월 12일 / 2차 심사 2015년 1월 30일 / 게재승인 2015년 3월 6일

* 이아라: 이화여자대학교 사회과학대학 심리학과를 졸업하고, 동대학원 심리학과 상담심리전공에서 석사학위를 취득하였으 며, 서울대학교 교육학과 교육상담전공에서 박사학위를 취득하였다. 현재 건양대학교 재활복지교육대학 심리상담치료학과 조교수로 재직 중이다.

*E-mail: dreammaker@konyang.ac.kr

* 이주영: 서울대학교 사범대학 생물교육학과를 졸업하고, 동대학원 협동과정 특수교육전공과 교육학과 교육상담전공에서 석사학위를 취득하였으며, 동대학원 교육학과 교육상담전공에서 박사학위를 취득하였다. 현재 호남대학교 인문사회대학 상담심리학과 조교수로 재직 중이다.

*E-mail: ljy@honam.ac.kr 
Abstract

\section{The Difference in Career Decision According to Intolerance of Uncertainty and Career Decision-Making Self Efficacy}

Lee, $\mathrm{A}-\mathrm{Ra}^{*}$

Lee, Juyoung ${ }^{* *}$

It is important to identify problems of college students who have difficulties in career decision and to intervene appropriately because career decision making is important developmental task in this period. In order to aid suitably for each problem, the symptoms and causes of problems need to be organized by classification in various dimensions. The purpose of this study is to verify the difference of the level of career indecision and causes of career indecision according to groups typed by two dimensions including career decision-making self efficacy and intolerance of uncertainty. 250 college students in 12 schools completed five instruments and 238 data among them were analyzed in this study. In results, the level of career decision-making and career preparation behavior is different statistically depending on the career decision-making self efficacy instead of the intolerance of uncertainty. However, the causes of indecision is different significantly according to the intolerance of uncertainty in spite of the same level of career decision-making self efficacy. The results show that it is necessary to consider not only career decision-making self efficacy but also intolerance of uncertainty for providing concrete treatment in solving career indecision problem. The clinical and research implications of these results are also suggested based on the results.

Key words: career decision-making self efficacy, intolerance of uncertainty, typing, the level of career decision-making, career decision-making problem, career preparation behavior

* First author, Assistant Professor, Konyang University

** Corresponding author, Assistant Professor, Honam University 
